\title{
Renin-angiotensin system modulators and other risk factors in COVID-19 patients with hypertension: a Korean perspective
}

\author{
Hee-Sung $\mathrm{Kim}^{1+}{ }^{\mathbb{D}}$, Minseok $\mathrm{Kang}^{2+}$ (D) and Gilwon Kang ${ }^{2,3^{*}}$ (B)
}

\begin{abstract}
Background: While hypertension is the most common comorbid condition in patients with coronavirus disease 2019 (COVID-19) in Korea, there is a lack of studies investigating risk factors in COVID-19 patients with hypertension in Korea. In this study, we aimed to examine the effects risk factors in hypertensive Korean COVID-19 patients.

Methods: We selected patients from the database of the project \#OpenData4Covid19. This information was linked to their 3-year historical healthcare data. The severity of the disease was classified into five levels. We also clustered the levels into two grades.

Results: The risk factors associated with COVID-19 severity were old age, diabetes mellitus, cerebrovascular disease, chronic obstructive pulmonary disease (COPD), malignancy, and renal replacement therapy. The use of angiotensin converting enzyme inhibitors (ACEls) or angiotensin receptor blockers (ARBs) both before and after a diagnosis of COVID-19 were not associated with COVID-19 severity. A multivariate analysis revealed that old age, male sex, diabetes mellitus, and renal replacement therapy were risk factors for severe COVID-19.

Conclusion: The results suggest that in hypertensive patients with COVID-19, older age, male sex, a diagnosis of diabetes mellitus, and renal replacement therapy were risk factors for a severe clinical course. In addition, the use of ARBs and ACEls before or after COVID-19 infection did not affect a patient's risk of contracting COVID-19 nor did it contribute to a worse prognosis for the disease. These results highlighted that precautions should be considered for hypertensive patients with those risk factors and do not support discontinuation of ARBs and ACEls during COVID-19 pandemic.
\end{abstract}

Keywords: COVID-19, Hypertension, Angiotensin receptor blocker (ARB), Angiotensin converting enzyme inhibitor (ACEI)

\footnotetext{
* Correspondence: gilwon67@chungbuk.ac.kr

${ }^{\dagger}$ Hee-Sung Kim and Minseok Kang contributed equally to this work.

${ }^{2}$ Department of Health Information and Management, Chungbuk National

University College of Medicine, 1 Chungdae-ro, Seowon-gu, Cheongju 28644, Republic of Korea

${ }^{3}$ Chungbuk Regional Cardiovascular Center, Chungbuk National University Hospital, Cheongju, Republic of Korea

Full list of author information is available at the end of the article
}

C C The Author(s). 2021 Open Access This article is licensed under a Creative Commons Attribution 4.0 International License, which permits use, sharing, adaptation, distribution and reproduction in any medium or format, as long as you give appropriate credit to the original author(s) and the source, provide a link to the Creative Commons licence, and indicate if changes were made. The images or other third party material in this article are included in the article's Creative Commons. licence, unless indicated otherwise in a credit line to the material. If material is not included in the article's Creative Commons licence and your intended use is not permitted by statutory regulation or exceeds the permitted use, you will need to obtain permission directly from the copyright holder. To view a copy of this licence, visit http://creativecommons.org/licenses/by/4.0/ The Creative Commons Public Domain Dedication waiver (http://creativecommons.org/publicdomain/zero/1.0/) applies to the data made available in this article, unless otherwise stated in a credit line to the data. 


\section{Background}

Among laboratory-confirmed cases of coronavirus disease (COVID-19), patients with underlying disease such as hypertension, diabetes, cardiovascular disease, respiratory disease, and malignancy have a poorer clinical outcome [1, 2]. In 2016, the percentage of the Korean population that was diagnosed with hypertension was $29.1 \%$ [3]. Due to its high prevalence, hypertension is the condition most comorbid with COVID-19 in Korea [4]. While hypertension is a known prognostic indicator of disease severity and mortality in COVID 19, it is not clear whether this link is due to the actual hypertensive condition itself, the presence of other comorbidities, or the type of anti-hypertensive treatment regimen being followed

There is also a debate concerning the role played by the angiotensin-converting enzyme 2 (ACE2) in the pathogenesis of COVID 19; angiotensin receptor blockers are the most frequently used monotherapy drugs in Korea [5]. The debate centers around the effect of RAS modulators such as ACE inhibitors (ACEIs) and angiotensin receptor blockers (ARBs) on severe acute respiratory syndrome coronavirus-2 (SARS-CoV-2) infectivity. One school of thought is that these renin-angiotensin system (RAS) modulators increase the risk of developing severe COVID-19, since ACE2 facilitates the entry of SARS-CoV-2 into the cell [6]. Another school of thought is that these RAS modulators improve the clinical outcome of COVID-19 by regulating the immune function and attenuating the inflammatory response [7].

In this study, we assessed the effects of RAS modulators and other risk factors in COVID-19 patients with hypertension in Korea.

\section{Methods}

\section{Patient selection and classification}

We selected patients selected from the database of the project \#OpenData4Covid19, a global research collaboration on COVID-19, hosted jointly by the Ministry of Health and Welfare of Korea and the Health Insurance Review and Assessment (HIRA) Service. The database contained information on the insurance benefit claims sent to HIRA including the data of all the patients that claimed for a COVID-19 test. This information was linked to their 3-year historical healthcare data. From January 3 to May 15, 2020, 234,427 individuals were tested for COVID-19, and 75,527 were diagnosed with hypertension. Of the 13,116 individuals that were on RAS modulators, 331 had a laboratory-confirmed COVID-19 diagnosis. HIRA data base contains every confirmed COVID-19 cases since it containing COVID-19 case is generated in the process of reimbursing providers and people with a COVID-19 test with a negative result maintained this status (If this people take their retest with positive results, this people turned into confirmed case). Of the 62,411 individuals that were not on any RAS modulators, 1580 had a laboratory- confirmed COVID-19 diagnosis. Laboratory diagnosis of COVID19 are being carried out by national central labs and 95 certified non-governmental clinical laboratories. Laboratory confirmed COVID-19 was defined by approved real-time PCR protocols targeting $E, R d R p$, $N$, orf1b, orf1a genes. For diagnostic testing for SARS-CoV-2, upper respiratory tract specimen and lower respiratory tract specimen were used. We excluded re-detected cases that test positive for SARS$\mathrm{CoV}-2$ after being discharged from isolation. Since it is considered that the genetic material of the "dead virus" remaining in a recovered patient's body is detected. A flow-chart of patient selection is presented in Fig. 1. This study was approved by the Institutional Review Board of Chungbuk National University Hospital (2020-04-015-001).

We merged the COVID-19 medical insurance claim data with the patient data and excluded cases of COVID-19 re-infection. The severity of the disease was classified into five levels: mild, moderate, severe, critical, and death. Each level of severity was defined according to the health insurance procedure code. Mild cases were defined by the lack of need for oxygen, moderate cases required oxygen therapy (M0040), severe cases required mechanical ventilation (MV) (M0850, M0857, M0858, M0860, M5830, M5850, M5857, M5858, M5860), and critical cases required extracorporeal membrane oxygenation (ECMO) (O1903, O1904). We also clustered the levels into two grades. Moderate, severe, critical, and death levels were clustered as Severity grade 1, while severe, critical, and death levels were clustered as Severity grade 2 .

Comorbidities was identified using the International Classification of Disease, 10th revision (ICD-10) codes: hypertension I10, diabetes mellitus E10-E14, cardiovascular disease (I11-I13), cerebrovascular disease (I60-I69), ischemic heart disease (I20-I25), and chronic obstructive pulmonary disease (J440, J441, J448, J449).

We used expanded benefit coverage codes or specific exemption codes for rare incurable diseases to identify malignancy (V193) and renal replacement therapy (V001, V003, V005). The use of ACEI and ARB was identified by their specific ATC code: angiotensinconverting enzyme (ACE) inhibitors (C09AA, C09BA, C09BB, C09Bx) and angiotensin-receptor II blockers (C09CA, C09DA, C09DB, C09DX).

We defined exposure to antihypertensive medication before diagnosis of COVID-19 as at least one prescription of antihypertensive medication from January 1, 


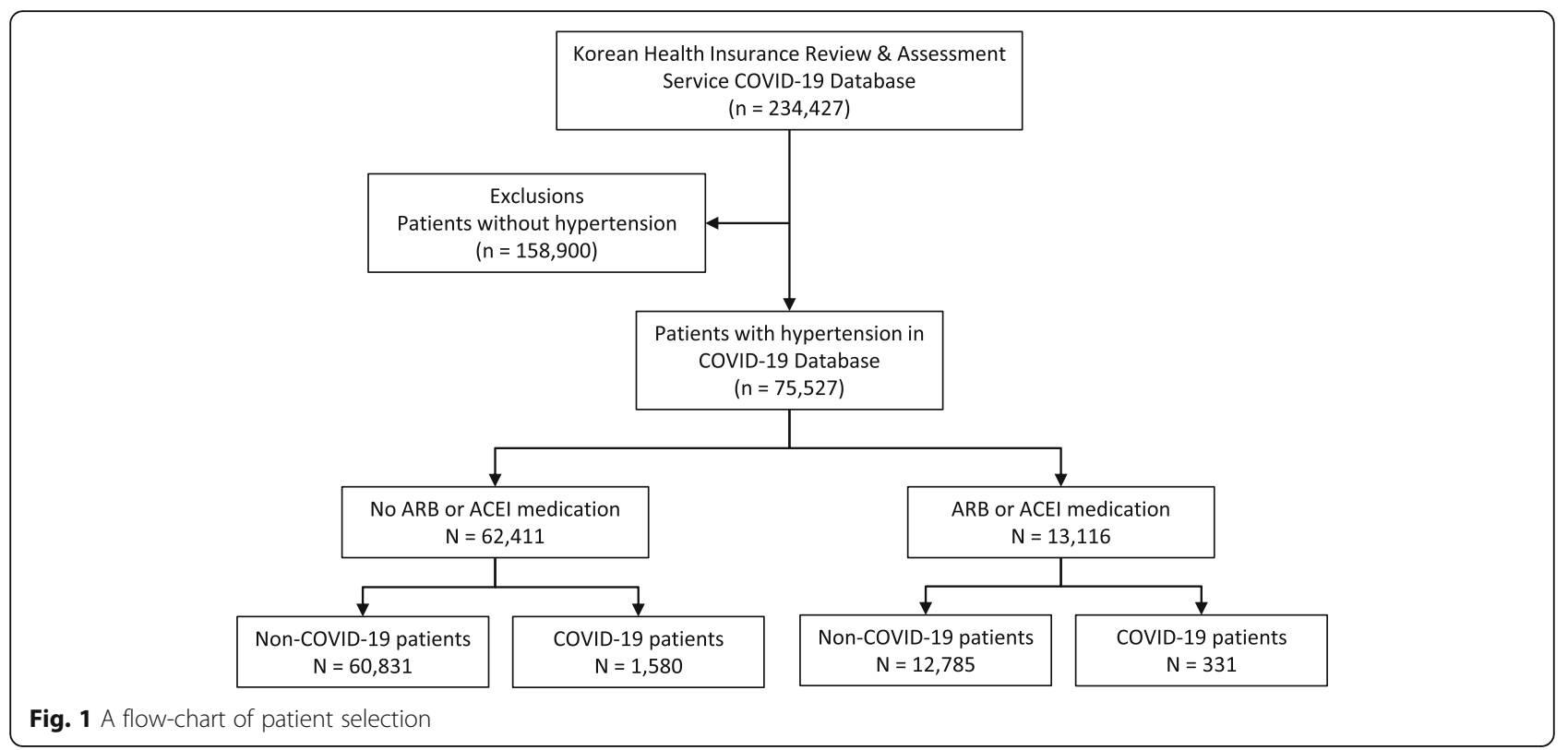

2020 until the diagnosis of COVID-19. This information was obtained from inpatient and outpatient prescription records of antihypertensive medication.

\section{Statistical analyses}

In the general characteristics of the analysis data, the subjects of hypertension and non-hypertension were classified, and the mean and median values for the continuous variable and the frequency and ratio for the categorical variable were indicated. In hypertensive patients, a chisquare test was performed for each independent variable, frequency and ratio, which are expected to affect COVID19 infection risk. In addition, multivariate logistic regression was performed to confirm the influence of the independent variable considering the interaction of each variable. The severity of COVID-19 patients was divided into five stages, and the independent variables, frequencies and ratios expected to affect clinical severity were analyzed by performing a chi-square test. Multivariate analysis was performed using logistic regression to evaluate the association between selected clinical characteristics and a likelihood of a positive test for COVID-19/ COVID-19 severity. SAS Enterprise Guide Software version 6.1 (SAS Institute Inc., Cary, NC) was used for these analyses, and a $P$ value of less than .05 was considered statistically significant.

\section{Results}

Table 1 reports the characteristics of the study population of patients tested for COVID-19. Until 15th May,

Table 1 Characteristics of the study population of patients tested for COVID-19

\begin{tabular}{|c|c|c|}
\hline Characteristics & $\begin{array}{l}\text { Patients with hypertension } \\
(N=75,527)\end{array}$ & $\begin{array}{l}\text { All patients } \\
(N=234,427)\end{array}$ \\
\hline Median age (interquartile rage)- yr. & $68(23)$ & $45(35)$ \\
\hline Female sex - no. (\%) & $35,761(47.3)$ & $122,480(52.2)$ \\
\hline Confirmed COVID-19- no. (\%) & $1911(2.5)$ & $7590(3.2)$ \\
\hline Diabetes mellitus- no. (\%) & $44,441(58.8)$ & $62,655(26.7)$ \\
\hline Cardiovascular disease- no. (\%) & $4705(6.2)$ & $5038(2.1)$ \\
\hline Cerebrovascular disease- no. (\%) & $14,503(19.2)$ & $17,519(7.5)$ \\
\hline Ischemic heart disease- no. (\%) & $12,122(16)$ & $14,191(6.1)$ \\
\hline COPD- no. (\%) & $4871(6.4)$ & $6612(2.8)$ \\
\hline Malignancy- no. (\%) & $14,368(19)$ & $24,628(10.5)$ \\
\hline Renal replacement therapy- no. (\%) & $4338(5.7)$ & $4525(1.9)$ \\
\hline ACEls or ARBs- no. (\%) & $13,116(17.4)$ & $13,240(5.6)$ \\
\hline
\end{tabular}


2020 , a total of 234,427 patients were tested for COVID19 and 7590 (3.2\%) had a positive result. Among the patients tested for COVID-19, 75,527 (32.2\%) had a history of hypertension; of these, 1911(2.5\%) were COVID19-positive and 13,116 (17.4\%) patients took ACE inhibitors or ARBs. Patients with hypertension were likely to be older and have more comorbidities than those without.

Compared to patients who tested negative for COVID19, those that tested positive were more likely to be younger (OR: 80.67) and women (OR 56.63) (Table 2). COVID-19 was confirmed more frequently in people without comorbidities, such as diabetes mellitus, cerebrovascular diseases, ischemic heart disease, COPD, malignancy, and renal replacement therapy. Use of ACEI or ARB was not different between two groups.

Multivariate analysis revealed that laboratory confirmed cases were less prevalent in males and individuals with cerebrovascular disease, ischemic heart disease, chronic obstructive pulmonary disease, malignancy, and renal replacement therapy (Table 3). Compared to the < 60 years age group, confirmed COVID-19 cases were more frequent in the 61-69 years age group; however, they were less frequent in the $\geq 80$ years age group.

Table 2 Characteristics of the patients with hypertension tested for COVID-19

\begin{tabular}{|c|c|c|c|}
\hline & COVID-19 (-) & COVID-19 (+) & Difference $(95 \% \mathrm{Cl})$ \\
\hline Age & & & $80.6791^{* * *}$ \\
\hline$<60$ & $22,850(0.97)$ & $665(0.03)$ & \\
\hline $61-69$ & $15,609(0.97)$ & $514(0.03)$ & \\
\hline $70-79$ & $17,899(0.98)$ & $418(0.02)$ & \\
\hline$\geq 80$ & $17,258(0.98)$ & $314(0.02)$ & \\
\hline Sex & & & $56.6345^{* * *}$ \\
\hline Male & $38,922(0.98)$ & $844(0.02)$ & \\
\hline Female & $34,694(0.97)$ & $1067(0.03)$ & \\
\hline Diabetes Mellitus & & & $29.5498^{* * *}$ \\
\hline Yes & $30,184(0.97)$ & $902(0.03)$ & \\
\hline No & 43,432 (0.98) & $1009(0.02)$ & \\
\hline Cardiovascular disease & & & 2.9933 \\
\hline Yes & $69,012(0.97)$ & $1810(0.03)$ & \\
\hline No & $4604(0.98)$ & $101(0.02)$ & \\
\hline Cerebrovascular disease & & & $26.7711^{* * *}$ \\
\hline Yes & $59,392(0.97)$ & $1632(0.03)$ & \\
\hline No & $14,224(0.98)$ & $279(0.02)$ & \\
\hline Ischemic heart disease & & & $52.4329^{* * *}$ \\
\hline Yes & $61,686(0.97)$ & $1719(0.03)$ & \\
\hline No & $11,930(0.98)$ & $192(0.02)$ & \\
\hline COPD & & & $53.0971^{* * *}$ \\
\hline Yes & $68,791(0.97)$ & $1865(0.03)$ & \\
\hline No & $4825(0.99)$ & $46(0.01)$ & \\
\hline Malignancy & & & $180.4433^{* * *}$ \\
\hline Yes & $59,384(0.97)$ & $1775(0.03)$ & \\
\hline No & $14,232(0.99)$ & $136(0.01)$ & \\
\hline Renal replacement therapy & & & $74.6484^{* * *}$ \\
\hline Yes & 69,301 (0.97) & $1888(0.03)$ & \\
\hline No & 4315 (0.99) & $23(0.01)$ & \\
\hline ACEls or ARBs & & & 0.0028 \\
\hline Yes & $12,785(0.97)$ & $331(0.03)$ & \\
\hline No & $60,831(0.97)$ & $1580(0.03)$ & \\
\hline
\end{tabular}

${ }^{*} \boldsymbol{P}<.05 ;{ }^{* *} \boldsymbol{P}<.01 ;{ }^{* * *} \boldsymbol{P}<.001$ 
Table 3 A multivariate analysis of a likelihood of a positive test for COVID-19

\begin{tabular}{lll}
\hline & COVID $-\mathbf{1 9}(+)$ & Difference $\mathbf{9 5 \%}$ Cl) \\
\hline ACEIs or ARBs & $1.01(0.89-1.13)$ & 0.9345 \\
$61-69$ & $1.36(1.2-1.53)$ & $<.0001$ \\
$70-79$ & $1.03(0.91-1.18)$ & 0.3633 \\
$\geq 80$ & $0.7(0.6-0.8)$ & $<.0001$ \\
Female & $1.33(1.21-1.46)$ & $<.0001$ \\
Diabetes mellitus & $0.92(0.84-1.01)$ & 0.0739 \\
Cardiovascular disease & $0.89(0.73-1.09)$ & 0.2599 \\
Cerebrovascular disease & $0.76(0.67-0.87)$ & $<.0001$ \\
Ischemic heart disease & $0.65(0.55-0.75)$ & $<.0001$ \\
COPD & $0.43(0.32-0.58)$ & $<.0001$ \\
Malignancy & $0.31(0.26-0.37)$ & $<.0001$ \\
Renal replacement therapy & $0.19(0.13-0.29)$ & $<.0001$ \\
\hline
\end{tabular}

${ }^{*} \boldsymbol{P}<.05 ;{ }^{* *} \boldsymbol{P}<.01 ;{ }^{* * *} \boldsymbol{P}<.001$

Univariate analysis of risk factors associated with COVID-19 severity revealed that old age, diabetes mellitus, cerebrovascular disease, COPD, malignancy, and renal replacement therapy were significant risk factors for severe COVID-19 (Table 4). Use of ACEI or ARB before or after diagnosis of COVID-19 was not associated with the severity of COVID-19. Patients were grouped according to level of care, we analyzed risk factors between mild cases and severity grade 1 (moderate, severe, critical), mild or moderate cases and severity grade 2 (severe, critical) and death cases and others (mild, moderate, severe, critical). Multivariate analysis revealed that old age, male sex, diabetes mellitus, and renal replacement therapy were risk factors for severity of COVID-19 (Table 5).

\section{Discussion}

Being older and of the male sex have been described as risk factors for a highly severe disease course in patients with COVID-19 [4, 8]. In China, case fatality rate (CFR) for those $\geq 80$ years of age was $14.8 \%$ and in Korea, it was $14 \%$. The CFR was also much higher in regions with collapsed health care systems. A recent study showed that men had a higher case of fatality that was independent of age $[8,9]$ This finding is thought to be due reasons such as gender specific life behavior patterns or sex differences in immune responses $[10,11]$. Another report from China indicated that ACE2 levels which are correlated with organ failure are higher in men than women [12]. Caution should be taken to treat COVID-19 patient with diabetes mellitus, since patients with diabetes mellitus have a poorer prognosis especially when metabolic complications of pre- existing diabetes are observed [13]. In our study of hypertensive patients with COVID-19, older age, male sex, a diagnosis of diabetes mellitus, and renal replacement therapy were risk factor for a more severe clinical prognosis for the disease.

While recent studies have implicated the presence of comorbidities as well as pro-inflammatory and procoagulative states in severe COVID-19 outcomes, SARSCoV-2 itself also has a negative effect on beta cell functions, precipitating acute metabolic complications [14]. Patients on dialysis have depressed immune systems and usually have other comorbidities [15]. A meta-analysis has shown that chronic kidney disease (CKD) seems to be associated with an enhanced risk of severe COVID19 infection [16]. These patients are also at a higher risk of contracting COVID-19, since the in-center hemodialysis units are often very densely populated. Our data indicated that patients on dialysis are at greater risk of severe COVID-19 infection.

There are conflicting reports on the effects of ARBs or ACEIs on the clinical results of patients with COVID-19. While clinical evidence indicates that these drugs can protect the lung from pneumonia and reduce SARS$\mathrm{CoV}-2$-induced lung injury [17], other researchers recommend discontinuing their use on the grounds that their use may enhance the risk of COVID-19. This is based on experimental findings that ARBs upregulate $\mathrm{ACE}$ and may thus enhance viral uptake and increase its virulence [5].

SARS-CoV-2 uses the ACE2 receptor for entry into the cell, and there have been concerns about whether these RAS modulators can upregulate the ACE2 receptor and modify susceptibility to COVID-19 [18].

Current research has demonstrated that use of either ACEIs or ARBs does not increase the likelihood of a positive test, and experts recommend that ACEI and ARB treatment regimens not be withdrawn [19]. The prevailing consensus is that being on either an ARB or ACEI treatment protocol, is not associated with a higher risk of testing positive for COVID-19. After adjusting age, sex and comorbidities, our study confirms that the use of ARBs and ACEIs is not associated with a greater severity of COVID-19 and supports the view that patients on ACEI or ARB treatment regimens should continue their medication as prescribed.

Our study has four limitations. First, the findings cannot be generalized to the general population due to the inhomogeneity of the study population. From February 18 until May 15, 2020 the large number of COVID-19 cases in Korea stemmed from a religious group in the Daegu and Gyeongbuk provinces and we were not able to correlate data regarding religion, contact with a confirmed case, and real area of 
Table 4 Risk factors associated with COVID-19 severity

\begin{tabular}{|c|c|c|c|c|c|c|}
\hline & Room air & $\mathrm{O}_{2}$ supply & MV & ECMO & Death & Difference $(95 \% \mathrm{Cl})$ \\
\hline Age & & & & & & $335.0999 * * *$ \\
\hline$<60$ & $579(0.87)$ & $72(0.11)$ & $4(0.01)$ & $1(0)$ & $9(0.01)$ & \\
\hline $61-69$ & $363(0.71)$ & $115(0.22)$ & $10(0.02)$ & $3(0.01)$ & $23(0.04)$ & \\
\hline $70-79$ & $246(0.59)$ & $113(0.27)$ & $6(0.01)$ & $1(0)$ & $52(0.12)$ & \\
\hline$\geq 80$ & $134(0.43)$ & $78(0.25)$ & $4(0.01)$ & $1(0)$ & $97(0.31)$ & \\
\hline Sex & & & & & & 6.3159 \\
\hline male & $562(0.67)$ & $174(0.21)$ & $13(0.02)$ & $3(0)$ & $92(0.11)$ & \\
\hline female & $760(0.71)$ & $204(0.19)$ & $11(0.01)$ & $3(0)$ & $89(0.08)$ & \\
\hline Diabetes mellitus & & & & & & $40.4894^{* * *}$ \\
\hline No & $683(0.76)$ & $151(0.17)$ & $11(0.01)$ & $3(0)$ & $54(0.06)$ & \\
\hline yes & $639(0.63)$ & $227(0.22)$ & $13(0.01)$ & $3(0)$ & $127(0.13)$ & \\
\hline Cardiovascular disease & & & & & & 1.1868 \\
\hline No & $1255(0.69)$ & $357(0.2)$ & $22(0.01)$ & $6(0)$ & $170(0.09)$ & \\
\hline Yes & $67(0.66)$ & $21(0.21)$ & $2(0.02)$ & $0(0)$ & $11(0.11)$ & \\
\hline Cerebrovascular disease & & & & & & $24.6214^{* * *}$ \\
\hline No & $1158(0.71)$ & $309(0.19)$ & $22(0.01)$ & $6(0)$ & $137(0.08)$ & \\
\hline Yes & $164(0.59)$ & $69(0.25)$ & $2(0.01)$ & $0(0)$ & $44(0.16)$ & \\
\hline Ischemic heart disease & & & & & & 8.4676 \\
\hline No & $1204(0.7)$ & $334(0.19)$ & $20(0.01)$ & $6(0)$ & $155(0.09)$ & \\
\hline Yes & $118(0.61)$ & $44(0.23)$ & $4(0.02)$ & $0(0)$ & $26(0.14)$ & \\
\hline COPD & & & & & & $12.8381^{*}$ \\
\hline No & $1300(0.7)$ & $363(0.19)$ & $24(0.01)$ & $6(0)$ & $172(0.09)$ & \\
\hline Yes & $22(0.48)$ & $15(0.33)$ & $0(0)$ & $0(0)$ & $9(0.2)$ & \\
\hline Malignancy & & & & & & $11.4142^{*}$ \\
\hline No & $1241(0.7)$ & $348(0.2)$ & $22(0.01)$ & $6(0)$ & $158(0.09)$ & \\
\hline Yes & $81(0.6)$ & $30(0.22)$ & $2(0.01)$ & $0(0)$ & $23(0.17)$ & \\
\hline Renal replacement therapy & & & & & & $18.3735^{* * *}$ \\
\hline No & $1315(0.7)$ & $367(0.19)$ & $24(0.01)$ & $6(0)$ & $176(0.09)$ & \\
\hline Yes & $7(0.3)$ & $11(0.48)$ & $0(0)$ & $0(0)$ & $5(0.22)$ & \\
\hline $\begin{array}{l}\text { ARB/ACEI use before } \\
\text { COVID-19 diagnosis }\end{array}$ & & & & & & 0.5448 \\
\hline No & $1094(0.69)$ & $310(0.2)$ & $19(0.01)$ & $5(0)$ & $152(0.1)$ & \\
\hline Yes & $228(0.69)$ & $68(0.21)$ & $5(0.02)$ & $1(0)$ & $29(0.09)$ & \\
\hline $\begin{array}{l}\text { ARB/ACEI use after } \\
\text { COVID-19 diagnosis }\end{array}$ & & & & & & 8.7247 \\
\hline No & $1259(0.6)$ & $355(0.2)$ & $21(0.01)$ & $5(0)$ & $177(0.1)$ & \\
\hline Yes & $63(0.67)$ & $23(0.24)$ & $3(0.03)$ & $1(0.01)$ & $4(0.04)$ & \\
\hline
\end{tabular}

${ }^{*} \boldsymbol{P}<.05 ;{ }^{* *} \boldsymbol{P}<.01 ; * * * \boldsymbol{P}<.001$

residence. Therefore, in our study, the COVID-19 exposure risk and the susceptibility to COVID-19 may be biased. Second, we were not able to analyze laboratory data and data regarding antiviral and steroid usage. Third, the severity of cases was identified and analyzed for all cases. Therefore, the level of severity may have been underestimated, because many of the open cases could end in death. Fourth, actual drug exposure to RAS modulators could not be quantified since the electronic health data did not include detailed data regarding patient compliance and the dose of the medication used. 
Table 5 A multivariate analysis of risk factors for COVID-19 severity

\begin{tabular}{|c|c|c|c|c|c|c|}
\hline & Severity grade & & Severity grade $2 \dagger$ & & Death $\neq$ & \\
\hline & Odds Ratio & $P$ & Odds Ratio & $P$ & Odds Ratio & $P$ \\
\hline ARB/ACEI use before COVID- 19 diagnosis & $1.05(0.79-1.39)$ & 0.759 & $0.99(0.65-1.51)$ & 0.9556 & $1(0.63-1.58)$ & 0.9851 \\
\hline ARB/ACEI use after COVID- 19 diagnosis & $1.35(0.83-2.2)$ & 0.2206 & $0.92(0.41-2.03)$ & 0.8279 & $0.5(0.17-1.44)$ & 0.1978 \\
\hline Age group: 61-69 & $2.89(2.13-3.93)$ & 0.0685 & $3.48(1.84-6.58)$ & 0.0175 & $3.38(1.53-7.46)$ & 0.0033 \\
\hline Age group: 70-79 & $4.76(3.47-6.53)$ & 0.0002 & $7.48(4.05-13.83)$ & 0.0045 & $9.99(4.76-20.99)$ & 0.0008 \\
\hline Age group: $\geq 80$ & $9.69(6.9-13.59)$ & $<.0001$ & $24.66(13.48-45.13)$ & $<.0001$ & $35.89(17.31-74.43)$ & $<.0001$ \\
\hline Female & $0.66(0.53-0.82)$ & 0.0001 & $0.52(0.38-0.72)$ & $<.0001$ & $0.51(0.36-0.73)$ & 0.0002 \\
\hline Diabetes mellitus & $1.46(1.17-1.81)$ & 0.0007 & $1.63(1.17-2.27)$ & 0.0038 & $1.79(1.24-2.57)$ & 0.0018 \\
\hline Cardiovascular disease & $0.98(0.62-1.56)$ & 0.9361 & $0.93(0.48-1.78)$ & 0.8206 & $0.88(0.43-1.77)$ & 0.7089 \\
\hline Cerebrovascular disease & $1.16(0.87-1.54)$ & 0.3179 & $1.08(0.73-1.58)$ & 0.7028 & $1.23(0.82-1.84)$ & 0.3121 \\
\hline Ischemic heart disease & $0.99(0.71-1.38)$ & 0.9361 & $0.97(0.62-1.53)$ & 0.8956 & $0.93(0.57-1.52)$ & 0.7828 \\
\hline COPD & $1.44(0.76-2.69)$ & 0.2611 & $0.92(0.41-2.05)$ & 0.8334 & $1.04(0.46-2.34)$ & 0.9345 \\
\hline Malignancy & $1.17(0.79-1.73)$ & 0.4253 & $1.36(0.82-2.24)$ & 0.2299 & $1.45(0.85-2.44)$ & 0.17 \\
\hline $\begin{array}{l}\text { Renal replacement } \\
\text { therapy }\end{array}$ & $9.99(3.82-26.1)$ & $<.0001$ & $4.13(1.31-13.02)$ & 0.0154 & $5.64(1.71-18.58)$ & 0.0045 \\
\hline
\end{tabular}

* Severity grade 1 (moderate, severe, critical and death cases) was defined as a more serious cases than mild cases. Severity grade 1 was compared with mild cases

† Severity grade 2(severe, critical and death cases) was defined as a more serious cases than moderate cases. Severity 2 grade was compared with mild or moderate cases

‡ Death cases were compared with mild, moderate, severe, critical cases

\section{Conclusions}

In conclusion, we found that in hypertensive patients with COVID-19, older age, male sex, a diagnosis of diabetes mellitus, and renal replacement therapy were risk factors for a severe clinical course. In addition, the use of ARBs and ACEIs before or after COVID19 infection did not affect a patient's risk of contracting COVID-19 nor did it contribute to a worse prognosis. To prioritize at-risk populations and allocate resource, precautions should be considered for hypertensive patients with those risk factors and our data do not support discontinuation of ARBs and ACEIs during COVID-19 pandemic.

\section{Abbreviations}

ACEIs: Angiotensin Converting Enzyme Inhibitors; ARBs: Angiotensin Receptor Blockers; ACE2: Angiotensin Converting Enzyme 2; COVID19: Coronavirus Disease 2019; COPD: Chronic obstructive pulmonary disease; CFR: Case fatality rate; CKD: Chronic kidney disease; ECMO: Extracorporeal membrane oxygenation; HIRA: Health Insurance Review and Assessment: ICD: International Classification of Disease; MV: Mechanical ventilation; RAS: Renin-Angiotensin System; SARS-CoV-2: Severe Acute Respiratory Syndrome Coronavirus-2

\section{Acknowledgments}

This research was supported by the Medical Research Information Center (MedRIC) through the National Research Foundation of Korea (NRF), funded by the Ministry of Science and ICT of Korean Government (NRF No. 2020R1A6A6018661).

\section{Authors' contributions}

HSK, GK designed this study. MK, HSK, GK conducted data collection and analysis of results. HSK wrote the first draft of manuscript. HSK and MK substantively revised manuscript. All authors were involved in finalizing the manuscript and approved the final version of the manuscript.
Funding

Not applicable.

Availability of data and materials

The claim data provided by Health Insurance Review and Assessment Service are not publicly available since HIRA put an end to the collaboration project (\#OpenData4Covid19) on July 31, 2020. Thus, we cannot share the data we used for this study with other researchers.

\section{Ethics approval and consent to participate}

This study was approved by the institutional review board of Chungbuk National University Hospital (IRB number: 2020-04-015-001). Because Health Insurance Review and Assessment Service of Korea deliver the analysis result values with analysis code that researchers produce, written informed consent was waived by the institutional review board. The data used in this study was anonymized before its use.

\section{Consent for publication}

Not applicable.

\section{Competing interests}

All authors declare that there are no conflicts.

\section{Author details}

'Department of Internal Medicine, Chungbuk National University College of Medicine, Cheongju, Republic of Korea. ${ }^{2}$ Department of Health Information and Management, Chungbuk National University College of Medicine, 1 Chungdae-ro, Seowon-gu, Cheongju 28644, Republic of Korea. ${ }^{3}$ Chungbuk Regional Cardiovascular Center, Chungbuk National University Hospital, Cheongju, Republic of Korea.

Received: 21 September 2020 Accepted: 28 January 2021

Published online: 15 February 2021

References

1. W-j G, Liang W-h, Zhao Y, Liang H-r, Z-s C, Y-m L, X-q L, R-c C, C-I T, Wang T. Comorbidity and its impact on 1590 patients with Covid-19 in China: A Nationwide Analysis. Eur Respir J. 2020:55(5). 
2. Hong KH, Lee SW, Kim TS, Huh HJ, Lee J, Kim SY, Park J-S, Kim GJ, Sung H, Roh KH. Guidelines for laboratory diagnosis of coronavirus disease 2019 (COVID-19) in Korea. Annals of laboratory medicine. 2020;40(5):351-60.

3. Lee J-H, Kim K-I, Cho M-C. Current status and therapeutic considerations of hypertension in the elderly. The Korean journal of internal medicine. 2019; 34(4):687.

4. Sung HK, Kim JY, Heo J, Seo H, Jang YS, Kim H, Koh BR, Jo N, Oh HS, Baek YM. Clinical course and outcomes of 3,060 patients with coronavirus disease 2019 in Korea, January-may 2020. J Korean Med Sci. 2020;35(30):e280.

5. Zheng Y, Ma Y, Zhang J, Xie X. COVID-19 and the cardiovascular system [published online ahead of print March 5, 2020]. Nat Rev Cardiol. 2020.

6. Kim HC, Cho M-C. Korea hypertension fact sheet 2018. Clinical hypertension. 2018;24(1):1-4

7. Meng J, Xiao G, Zhang J, He X, Ou M, Bi J, Yang R, Di W, Wang Z, Li Z. Renin-angiotensin system inhibitors improve the clinical outcomes of COVID-19 patients with hypertension. Emerging microbes \& infections. 2020;9(1):757-60.

8. Jin J-M, Bai P, He W, Wu F, Liu X-F, Han D-M, Liu S, Yang J-K. Gende differences in patients with COVID-19: focus on severity and mortality. Front Public Health. 2020;8:152.

9. Du Y, Tu L, Zhu P, Mu M, Wang R, Yang P, Wang $X, H u$ C, Ping R, Hu P. Clinical features of 85 fatal cases of COVID-19 from Wuhan. A retrospective observational study. Am J Respir Crit Care Med. 2020;201(11):1372-9.

10. Klein SL, Dhakal S, Ursin RL, Deshpande S, Sandberg K, Mauvais-Jarvis F. Biological sex impacts COVID-19 outcomes. PLoS Pathog. 2020;16(6): e1008570.

11. Gebhard C, Regitz-Zagrosek V, Neuhauser H, Morgan R, Klein S. Impact of sex and gender on COVID-19 outcomes in europe. Biol sex differ. 2020;11: 29.

12. Patel SK, Velkoska E, Burrell LM. Emerging markers in cardiovascular disease: where does angiotensin-converting enzyme 2 fit in? Clin Exp Pharmacol Physiol. 2013;40(8):551-9.

13. N-y K, Ha E, Moon JS, Lee Y-H, Choi EY. Acute hyperglycemic crises with coronavirus Disease-19. Diabetes \& Metabolism Journal. 2020;44(2):349.

14. Apicella M, Campopiano MC, Mantuano M, Mazoni L, Coppelli A, Del Prato S. COVID-19 in people with diabetes: understanding the reasons for worse outcomes. The lancet Diabetes \& endocrinology. 2020.

15. Rabb H. Kidney diseases in the time of COVID-19: major challenges to patient care. J Clin Invest. 2020;130(6):2749-51.

16. Henry BM, Lippi G. Chronic kidney disease is associated with severe coronavirus disease 2019 (COVID-19) infection. Int Urol Nephrol. 2020:1-2.

17. Fedson DS. Treating the host response to emerging virus diseases: lessons learned from sepsis, pneumonia, influenza and Ebola. Annals of translational medicine. 2016:4(21)

18. Vaduganathan M, Vardeny O, Michel T, McMurray JJ, Pfeffer MA, Solomon SD. Renin-angiotensin-aldosterone system inhibitors in patients with Covid-19. N Engl J Med. 2020;382(17):1653-9.

19. Saavedra JM. COVID-19, angiotensin receptor blockers, and the brain. Cell Mol Neurobiol. 2020;1.

\section{Publisher's Note}

Springer Nature remains neutral with regard to jurisdictional claims in published maps and institutional affiliations.

Ready to submit your research? Choose BMC and benefit from:

- fast, convenient online submission

- thorough peer review by experienced researchers in your field

- rapid publication on acceptance

- support for research data, including large and complex data types

- gold Open Access which fosters wider collaboration and increased citations

- maximum visibility for your research: over $100 \mathrm{M}$ website views per year

At $\mathrm{BMC}$, research is always in progress.

Learn more biomedcentral.com/submissions 